\title{
NONLINEAR SIMULATION OF MASONRY VAULTS UNDER EARTHQUAKE LOADING
}

\author{
A. Plavsic ${ }^{1}$, B. Pantó ${ }^{1}$, C. Chisari ${ }^{2}$, L. Macorini ${ }^{1}$, B. A. Izzuddin ${ }^{1}$, I. Boem ${ }^{3}$, N. Gattesco ${ }^{3}$ \\ ${ }^{1}$ Department of Civil and Environmental Engineering Imperial College London \\ South Kensington Campus, London SW7 2AZ, UK \\ e-mail: \{adam.plavsic, b.panto, 1.macorini, b.Izzuddin\}@imperial.ac.uk \\ ${ }^{2}$ Department of Architecture and Industrial Design, Università della Campania "Luigi Vanvitelli" \\ via San Lorenzo - Abazia di San Lorenzo, Aversa (CE), Italy \\ e-mail: corrado.chisari@unicampania.it \\ ${ }^{3}$ Department of Engineering and Architecture, University of Trieste \\ Piazzale Europa, Trieste, Italy \\ e-mail: boem@ dicar.units.it gattesco@units.it
}

\begin{abstract}
Masonry vaults are present in a large number of historical structures and often used as flooring and roofing systems in monumental palaces and religious buildings, typically incorporating no backfill. Many of these structures are located in seismic regions and have been shown to be particularly vulnerable during recent earthquakes, with a need for accurate modelling to avoid future losses. Masonry vaults are often analysed using limit analysis procedures under the hypotheses of no-tension material and absence of sliding along the masonry joints. However, this method can be inaccurate for barrel vaults found in buildings, which are typically slender with no backfill. In this case, the masonry tensile strength and the progressive damage propagation play an important role in the nonlinear behaviour and ultimate strength of the vault. In this study, a detailed mesoscale finite element mesoscale approach is used to model slender unreinforced barrel vaults subjected to cyclic quasi-static and dynamic loading. According to this approach, 3D solid elements connected by $2 D$ damage-plasticity interfaces are used to represent the arrangement of bricks and mortar present in the masonry. The proposed numerical description is first validated against the results from physical tests on a barrel vault under quasi-static cyclic loading. Subsequently, the shear response of a prototype vault is analysed by performing nonlinear simulations under prescribed horizontal displacements at the supports, considering also the influence of previous damage induced by earthquakes with different magnitudes.
\end{abstract}

Keywords: Seismic risk, Historical masonry structures, Cyclic analyses, Nonlinear timehistory analyses, Discrete FEM approach, Mesoscale models. 


\section{INTRODUCTION}

Several existing buildings worldwide of historical, cultural and architectural significance incorporate vaulted masonry components. A high percentage of these buildings is located in high-seismic regions, and masonry vaults and domes have been observed to be particularly vulnerable under lateral loading imposed by earthquakes [1]. Hence, to prevent the potential loss of cultural heritage assets, there is a need to model both unreinforced masonry vaults and potential strengthening measures accurately to ensure protection of vaulted structures against future seismic events.

Masonry vaults are usually analysed using limit analysis procedures [2][3]. However, this approach provides only ultimate load predictions but no description of the behaviour of the structure up to failure. Furthermore, the assumptions of no-tension material and no-sliding along the mortar joints [4], often made in these methods, may lead to unrealistic results in the case of barrel vaults in buildings, which are typically slender, with high span to thickness ratios, and which do not include backfill thus sustaining very low compressive stresses [5].

To achieve accurate response predictions at different loading levels up to collapse, detailed finite element (FE) models based on mesoscale or macroscale masonry models can be used. The first strategy allows for the specific masonry bond utilising nonlinear zero-thickness interface elements [6] to predict the development of cracks at the mortar joints within brick units. This accurate modelling strategy has been previously adopted in [7] to investigate the cyclic behaviour of masonry structures under cyclic loading. Detailed work using the mesoscale approach has been carried out on masonry arched structures by Zhang et al. [8] and on multi-span masonry arch bridges by Tubaldi et al. [9].

The alternative is a macroscale smeared crack approach [10] in which masonry is assumed as a homogeneous isotropic material, and specific nonlinear material models based on damage and plasticity frameworks are typically utilised to represent the development and propagation of damage in the brickwork. An example of the latter is the use of a damage model proposed in [11], which uses homogenised mechanical parameters. Smeared crack models have also been used by Stablon et al. [12] and by Gattesco et al. [13,14] to model masonry vaults also in presence of strengthening systems.

A modelling approach, alternative to $\mathrm{FE}$ analysis, has been proposed in [15] and applied to simulate unreinforced and reinforced arches and vaults $[15,16]$. The model is composed of shear deformable macro-elements, interacting by means of non-linear zero-thickness interface elements which simulate the masonry flexural behaviour and potential shear sliding.

This study proposes a detailed FE mesoscale approach to model typical barrel vaults of religious buildings. The model allows for the inhomogeneity of masonry and the damage accumulated in reverse cycles of loading. The numerical results are validated against experimental results obtained through a new testing layout in which the vault is subjected to horizontal forces proportional to the structural self-mass [17]. Further numerical simulations have been conducted to investigate the ability of a representative barrel vault to transfer shear forces acting as a floor diaphragm in a building structure subjected to earthquake loading.

\section{THE MESOSCALE MODELING APPROACH}

The mesoscale approach used here has been developed at Imperial College [6] and applied to different extreme loading conditions [7-9]. According to this approach, the masonry is discretised into 3D solid brick elements separated by 2D zero thickness non-linear interface elements representing the mortar joints. As the thickness of the mortar joints is generally much smaller than the scale of the bricks, the collapsing of the mortar joints into interfaces is a suit- 
able simplification, but still captures the inherently nonlinear character of masonry as a material. This restricts the cracking to the predefined interfaces, which again is realistic in the context of masonry, where the joints act as preferential fracture planes. The interfaces are hence positioned to coincide with the mortar joints. Additional interfaces are placed in the midplane of each brick, in line with the head joints of adjacent bricks, to allow the propagation of cracks through the brick units themselves as observed in real masonry structures. This results in a regular, structured mesh, where the properties of the interfaces allow a physical representation of the 3D bond arrangement. This is important especially where 3D behaviour is of interest, in which case plane stress or plane strain assumptions can be unrepresentative of the true structure.

Specifically, for the vaults considered in this study, the bricks are modelled as 20-noded quadratic solid elements which for which the constitutive material response is linear elastic. All the material nonlinearity is captured by the 16-noded interface elements described by [6], hence the material model for these becomes of prime importance. Figure 1 shows the placement of joints to represent bed joints, head joints and brick failure surfaces. This allows the simulation of hinge formation, shear sliding and ring separation which are typical failure mechanisms for vaults and arches. A damage-plasticity constitutive law, proposed in [7], is employed for the interface elements. The plastic yield surface consists of three yield functions: two planar surfaces for mode I (tensile) and mode III (crushing) fracture which cap the ends of a conical Coulomb surface for mode II (shear) fracture. The level of damage in each mode is a function of the ratios the plastic work in tension $\left(W_{p l, t}\right)$, shear $\left(W_{p l, s}\right)$ and compression $\left(W_{p l, c}\right)$. Based on physical observations, the damage in tension is influenced by the plastic work in both tension and shear, the damage in shear is influenced by plastic work in all three modes, while damage in compression is only related to the plastic work in compression. Numerical results obtained by this model were found to be close to those of experimental data, with the main drawback of the approach being its high computational cost. This was eased by using a partitioning approach which allowed parallel computing to reduce run time $[8,18]$.

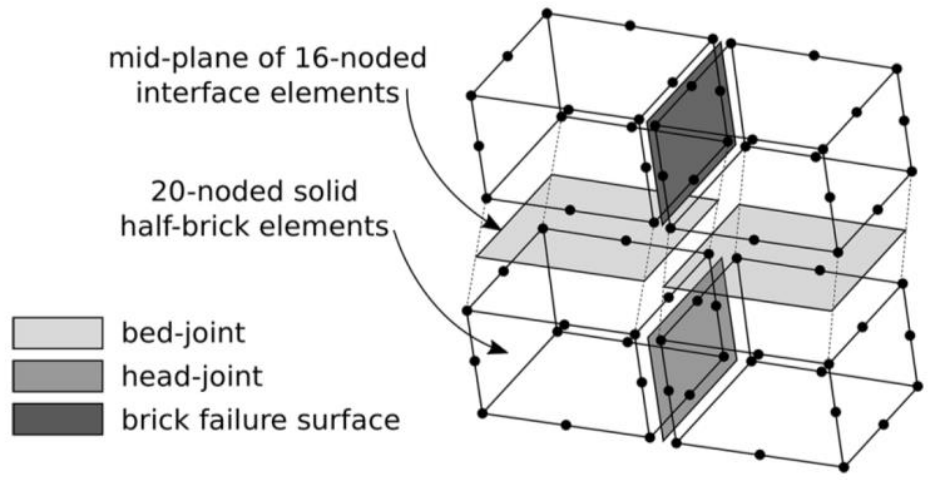

Figure 1: Brick and interface elements used in the mesoscale model $[6,7]$

\section{THE EXPERIMENTAL TESTS}

The numerical model applied in this study is validated against experimental results from [17] which used a novel bench setup to apply cyclic horizontal forces proportional to the mass of the arch. To elaborate, a quasi-static cyclic load was applied as a prescribed displacement by a hydraulic actuator and distributed evenly to 8 points either side of the vault by the frame shown in Figure 2a. The load was increased each cycle up to the failure of the vault.

The abutments were fixed during the test allowing no relative displacement. Two geometric layouts have been tested (Figure 2b): V75-NR (rise 1540mm, rise/span 0.75) and V50-NR (rise $1030 \mathrm{~mm}$, rise/span 0.5 ). Both were $120 \mathrm{~mm}$ thick and $770 \mathrm{~mm}$ wide, with a common ra- 
dius of $2060 \mathrm{~mm}$. The mortar joints were $10 \mathrm{~mm}$ thick on average. Differing lime mortars were used for each vault, with Young's Module tested as $9632 \mathrm{MPa}$ and $11790 \mathrm{MPa}$ for the V75NR and V50-NR tests, respectively. Flexural tests on masonry samples resulted in strengths of $0.42 \mathrm{MPa}$ (V75-NR) and $0.84 \mathrm{MPa}$ (V50-NR). Solid brick units with self-weight $15.64 \mathrm{kN} / \mathrm{m}^{3}$ were used for both vaults. The main results of interest were that collapse occurred via the formation of a hinge mechanism in all cases, with most specimens forming four hinges at failure [17].

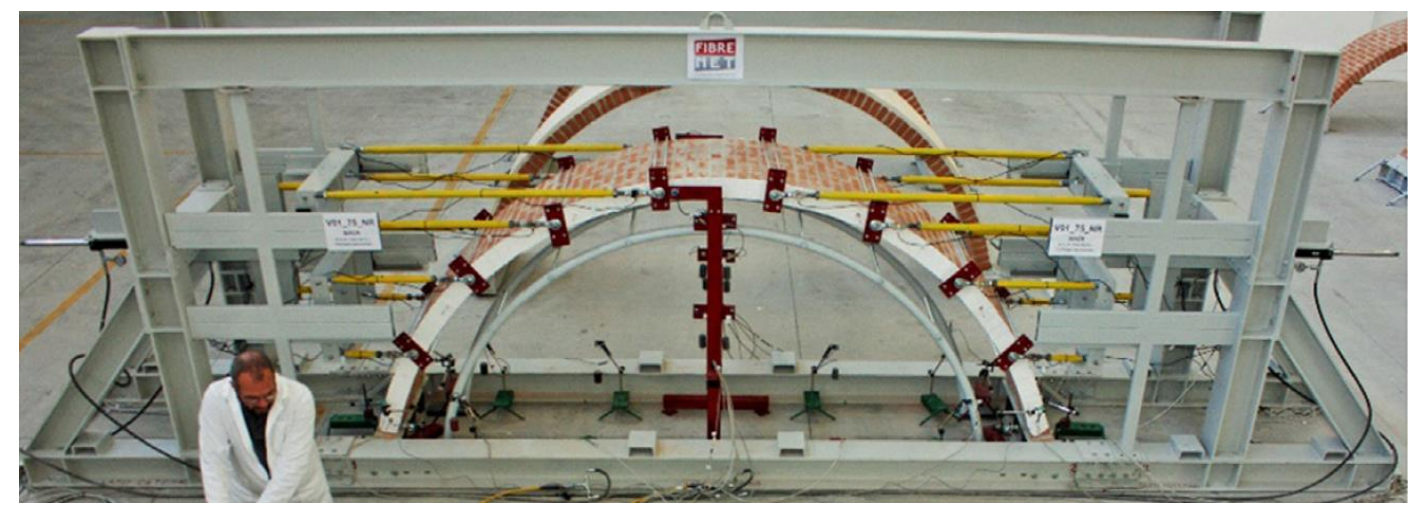

(a)
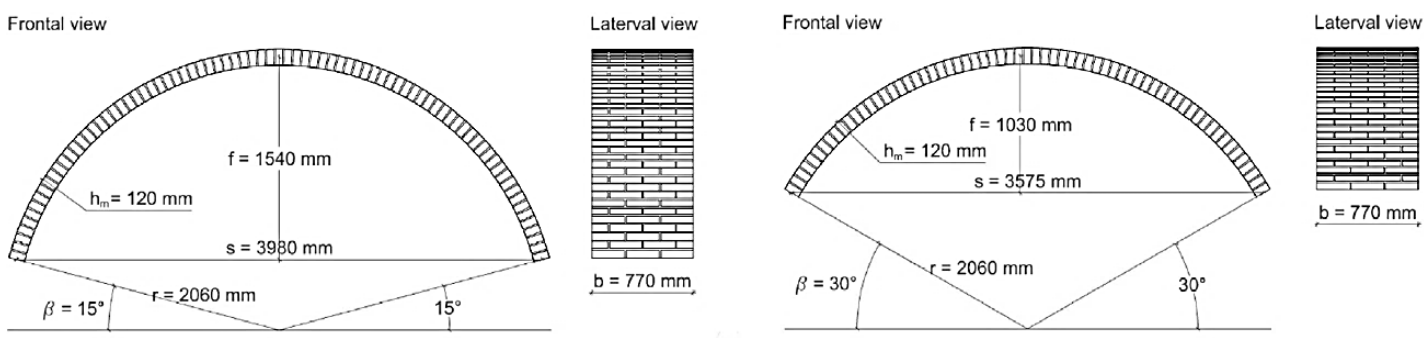

(b)

Figure 2: Test layout (a) and geometry of vaults (b) used in the experimental study [17].

\section{MODEL VALIDATION}

The full arrangement of bricks around the circumference is modelled using 20-noded solid brick elements for each brick, connected by 16-noded interface elements representing the mortar bed joints, following the modelling approach described in Section 2. As displacement perpendicular to the span was prevented in the test, the arrangement of head joints through the width of the arch is not modelled. Instead, a strip model is assumed, comprised of a single solid brick element for the width of strip. The reactions obtained are then scaled up accordingly by the ratio of the vault width to the strip thickness. The final brick at each skewback is not explicitly included in the numerical model, rather interface elements are placed at the end of each vault and fully fixed to represent the mortar joint to this fixed brick.

The experiment employed devices to prevent the inward or outward slip of the vault at the skewbacks and this is simulated by giving the interfaces at each skewback arbitrarily high shear strength and stiffness values, preventing shear sliding. In the experiment a device was used to oppose the uplift at each skewback. It is modelled by a linear spring with normal stiffness of $1.1 \mathrm{~N} / \mathrm{mm}$ arranged in parallel with the skewback interfaces. This value was obtained with reference to a subsequent numerical study performed in [17]. The model mesh is shown in Figure 3, with the zero-thickness interfaces shown as the full thickness of the mortar joints 
for clarity. To simulate the experimental loading arrangement, 3D dynamic analyses are performed employing spreader elements available in ADAPTIC [19] which allow an acceleration time history to be applied at a 'master' node and the resulting forces to be distributed according to predefined ratios at a number of 'slave' nodes. In the analyses, according to the experimental findings, the same ratio is applied to all "slave" nodes.

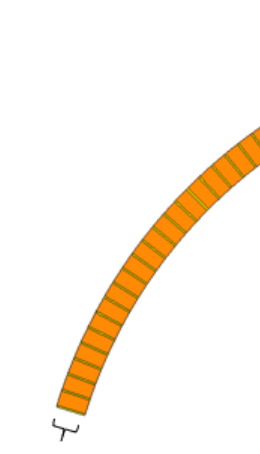

Fixed in $\mathrm{x}, \mathrm{y}, \mathrm{z}$

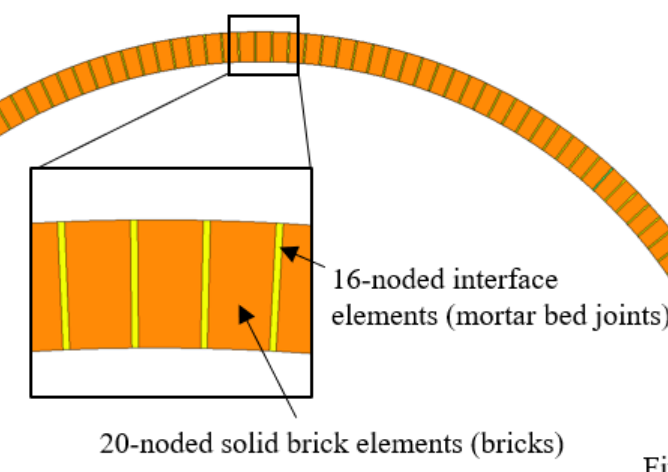

Figure 3: Mesh used for the vault V75-NR

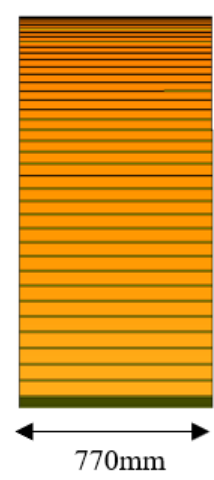

xed in $x, y, z$

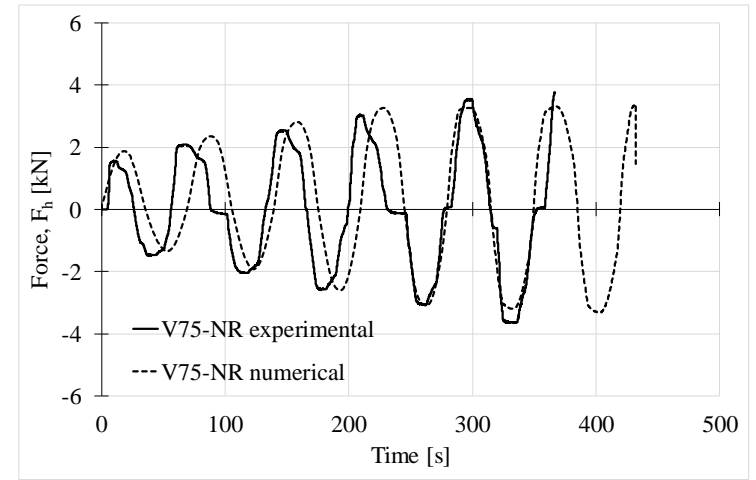

(b)

Figure 4: Displacement (a) and force (b) time-histories of the hydraulic actuator in the test and at the master node of the model.

Figure 4 shows the displacement history registered by the hydraulic actuator and those considered in the numerical analysis. Each analysis is performed in two separated phases: the self-weight of the vault is applied first as an initial load, then the lateral loads are applied by means of a displacement-control procedure. No viscous damping is considered in the analyses since it is expected negligible when compared to the hysteretic energy dissipation.

For both vaults, the interface tensile strength is calculated from the masonry tensile strength at the macroscopic scale according to [20]. The Young's modulus of the bricks is estimated applying a simple homogenization procedure and fixing arbitrary high values for the tangential and normal stiffness ( $k_{t}$ and $k_{n}$ ) according to [21]. The resulting Young's moduli are $4260 \mathrm{MPa}$ and 5280Mpa for the V75-NR and V50-NR specimens, respectively. Finally, Poisson's ratio 0.2 and specific weight $1664 \mathrm{kN} / \mathrm{m}^{3}$ are considered for both the two tests.

The parameters for the Coulomb model are taken from values obtained with reference a numerical study performed on the same experimental results [14], resulting a friction coefficient of 0.58 for both vaults and cohesion of $0.19 \mathrm{MPa}$ and $0.38 \mathrm{MPa}$ for vaults V75 and V50, respectively. The fracture energy for modes I and II are assumed in line with values from previous studies [21,22] where it was found that values for mode I (tensile) were typically in the 
range 0.01 to $0.08 \mathrm{~N} / \mathrm{mm}$ and for mode II (shear) from 0.1 to $0.2 \mathrm{~N} / \mathrm{mm}$. The fracture energy in mode $\mathrm{I}$ is assumed at a low value to reflect the brittle response observed experimentally. The set of parameters adopted for each vault are summarised in Tables 1 , where $k_{n}$ and $k_{t}$ are the normal and tangential elastic stiffness; $f_{t}, f_{c}$ and $c$ are the tensile strength, compression strength and cohesion; $\tan (\phi)$ and $\tan \left(\phi_{g}\right)$ are the friction and dilatancy coefficients; $G_{f, t}, G_{f, s}$ and $G_{f, c}$ are the fracture energy in tension, shear and compression, respectively.

\begin{tabular}{cccccccccccc}
\hline Test & $\begin{array}{c}k_{n} \\
{\left[\mathrm{~N} / \mathrm{mm}^{3}\right]}\end{array}$ & $K_{t}$ & $f_{t}$ & $\begin{array}{c}F_{c} \\
{[\mathrm{MPa}]}\end{array}$ & $c$ & $G_{f, t}$ & $\begin{array}{c}G_{f, s} \\
{[\mathrm{~N} / \mathrm{mm}]}\end{array}$ & $G_{f, c}$ & $\tan (\phi)$ & $\begin{array}{c}\tan \left(\phi_{g}\right) \\
{[-]}\end{array}$ & $\mu$ \\
\hline V75-NR & 1000 & 1000 & 0.14 & 5.00 & 0.19 & 0.01 & 0.125 & 1.0 & 0.58 & 0.00 & 0.1 \\
V50-NR & 1000 & 1000 & 0.28 & 6.20 & 0.38 & 0.05 & 0.125 & 1.0 & 0.58 & 0.00 & 0.1 \\
\hline
\end{tabular}

Table 1: Mechanical parameters of the mortar joint interfaces.

\section{CYCLIC QUASI-STATIC ANALYSIS}

All analyses are performed using the general nonlinear Finite Element software ADAPTIC [19]. The total horizontal force applied $\left(F_{h}\right)$ plotted against the horizontal displacement at the crown section $\left(\delta_{h}\right)$ is shown in Figure 5 and compared to the experimental hysteresis loops for both tests. The experiment on vault V75-NR exhibited an early hinge forming at one haunch in one loading direction, which is attributed to an imperfection in the mortar bond. This resulted in one skewback not cracking and led to an asymmetric response. To simulate this aspect, one artificially weakened skewback is introduced in the model considering a reduced tensile strength $\left(f_{t, \text { skew }}=0.01 \mathrm{MPa}\right)$. Moreover, it is noted that for both vaults the experimental results recorded a very high initial stiffness and very high unloading stiffnesses during cycles. This was a by-product of the testing rig arrangement and not representative of the physical behaviour of the vault. The numerical collapse mechanisms are shown in Figure 6, where the normal stress along the span $\left(s_{x x} \mathrm{MPa}\right)$ is represented. For the vault V75-NR, the model captured the formation of the 2 hinges at both skewbacks and then the third at the haunch. After this point, convergence was lost (Figure 6a). For the vault V50-NR, the first hinge occurred at the right skewback. Subsequently, the second and third hinges formed near simultaneously at the left skewback and right mid-span, then the $4^{\text {th }}$ hinge opened at the remaining haunch (Figure 6b). After 4 hinges are formed, a rocking motion involving the three uncracked spans sustained a residual load which increased to around $5 \mathrm{kN}$, at which point additional damage occurred near the skewbacks and the blocks lost shear strength, with the final sliding failure occurring at approximately $24 \mathrm{~mm}$. This mechanism was also observed experimentally, confirming the reliability and robustness of the interface model. Table 2 summarises the behaviour of each vault alongside the experimental results.

\begin{tabular}{cccc}
\hline Test & $F_{\max }[\mathrm{kN}]$ & $F_{\max , \exp }[\mathrm{kN}]$ & $\left(F_{\max }-F_{\max , \exp }\right) / F_{\max , \exp }[\mathrm{kN}]$ \\
\hline V75-NR & 3.37 & 3.76 & $-10 \%$ \\
V50-NR & 12.23 & 13.01 & $-6 \%$ \\
\hline
\end{tabular}

Table 2: Numerical $\left(F_{\max }\right)$ and experimental $\left(F_{\max , \exp }\right)$ horizontal peak loads. 


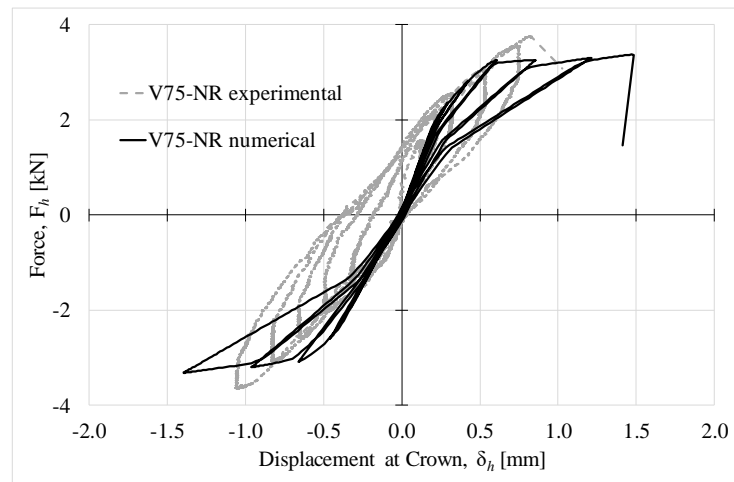

(a)

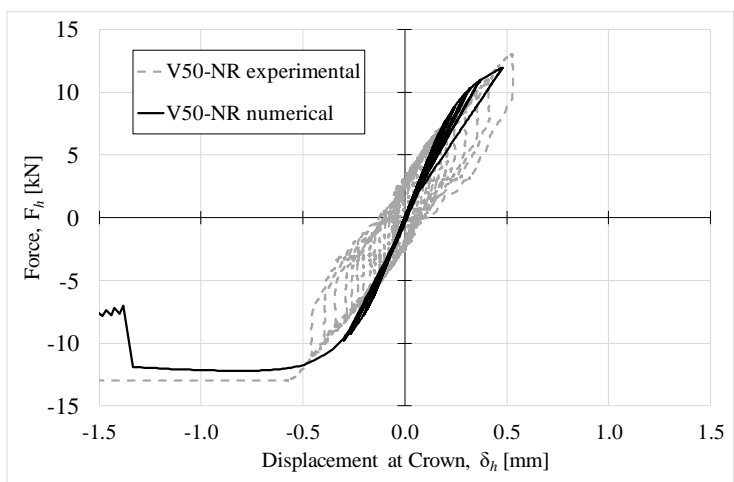

(b)

Figure 5: Experimental and numerical cyclic responses of vault specimens V75-NR (a) and V50-NR (b).

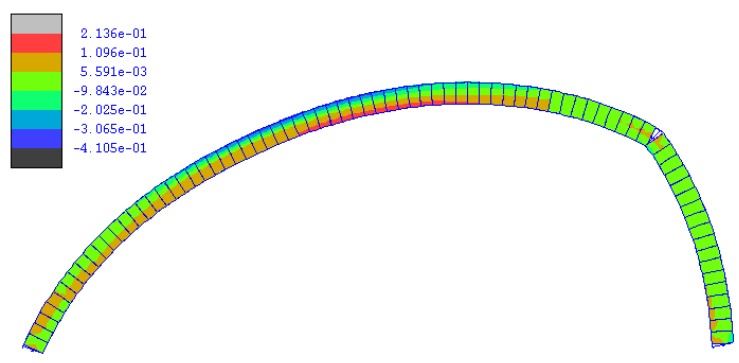

(a)

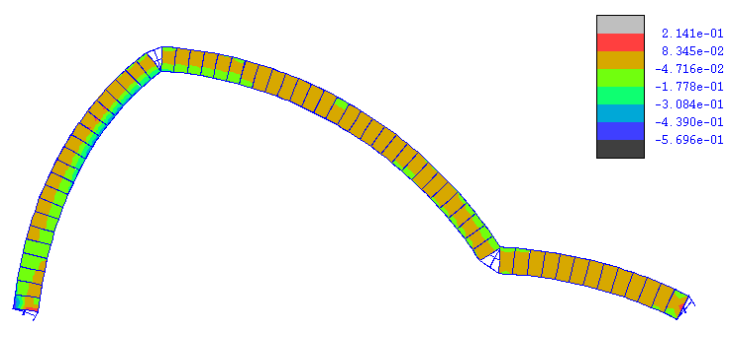

(b)

Figure 6: (a) Deformed shape of the V75-NR model at the activation of the $3^{\text {rd }}$ hinge; (b) deformed shape of the V55-NR model at the formation of the $4^{\text {th }}$ hinge (displacements scale: 100).

\section{NUMERICAL SIMULATIONS UNDER EARTHQUAKE LOADING}

In this section, the behaviour of the V75-NR prototype, subjected to a time-history acceleration, applied at each skewback, is investigated. The full mortar bond arrangement is modelled using two different types of interfaces to represent the mortar-brick head joints and the brickbrick joints. The later allowing cracks to form through the centre of each brick. By alternating the placement of these interfaces in the y direction, the realistic arrangement of bricks and mortar can be simulated. The brick-brick joint interfaces are calibrated, according to specific literature referring to similar masonry units [6], as no direct information was available experimentally on the specific brick properties required. These are presented in Table 3.

The earthquake record from Southern Italy Irpina earthquake (1980), Sturno station, is selected from the European Strong-Motion Database (ISESD) [23] with the linear baseline of the acceleration time history corrected. Two horizontal components (Figure 7) are simultaneously applied to the vault to observe the full 3D behaviour. The direction with the higher peak ground acceleration of $0.32 \mathrm{~g}$ is applied parallel to the span of the vault (x direction), while the record with PGA $0.22 \mathrm{~g}$ is applied perpendicular to the span (y direction). The original record is scaled up and down by 50\%. The resulting acceleration time histories scale the original record by factors of 0.5 (EQ0.5), 1.0 (EQ1.0) and 1.5 (EQ1.5), and the peak ground accelerations for each simulation are shown in the first two rows of Table 4. A further test used the unscaled record with peak ground acceleration $0.32 \mathrm{~g}$ applied only in the $\mathrm{x}$-direction (EQ1.0x) to explore the influence of the shaking in the y direction.

The numerical response under EQ1.0, in terms of horizontal displacement at the crown section versus the horizontal base shear, is plotted in Figure 8a, superposed onto the experimental 
results. Collapse is evidenced for cases EQ1.0 and EQ1.5, while the structure remains almost elastic for case of EQ0.5. These collapses correspond to the activation of four hinges.

\begin{tabular}{ccccccccccc}
\hline $\begin{array}{c}k_{n} \\
\begin{array}{c}K_{t} \\
{\left[\mathrm{~N} / \mathrm{mm}^{3}\right]}\end{array}\end{array}$ & $f_{t}$ & $\begin{array}{c}F_{c} \\
{[\mathrm{MPa}]}\end{array}$ & $c$ & $G_{f, t}$ & $\begin{array}{c}G_{f, s} \\
{[\mathrm{~N} / \mathrm{mm}]}\end{array}$ & $G_{f, c}$ & $\tan (\phi)$ & $\tan \left(\phi_{g}\right)$ & $\mu$ \\
\hline $1 \mathrm{E}+5$ & $1 \mathrm{E}+5$ & 1.67 & 20.77 & 2.8 & 0.05 & 0.125 & 1.0 & 1.0 & 1.0 & 0.1 \\
\hline
\end{tabular}

Table 3: Mechanical parameters of the brick-to-brick interfaces

In the three simulations EQ1.0, EQ1.5 and EQ1.0x, a four-hinge mechanism forms in the $\mathrm{x}$ direction, with two hinges at each skewback forming first, followed by hinges at the two haunches of each vault. In terms of the failure mechanism, the x-direction was dominant, with cracks forming along the full width of the bed joints. This is partially explained by the peak acceleration in the $\mathrm{x}$ direction being approximately 1.5 times that in the y-direction and considering the limited width of the vault.

Hinge locations are close to those obtained from the cyclic simulations. For the vaults accelerated in both directions, up until the formation of four hinges little deformation in the ydirection is observed, but once forms the vault lost shear stiffness along the cracked bed joints. Typically, a fifth hinge forms near to the crown, and rotation of the uncracked blocks is observed, as shown in Figure 8b for simulation EQ1.5.

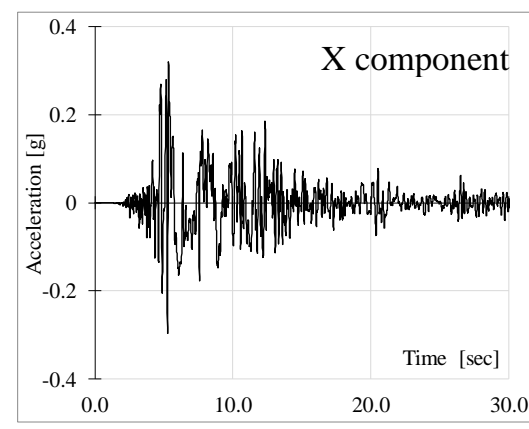

(a)

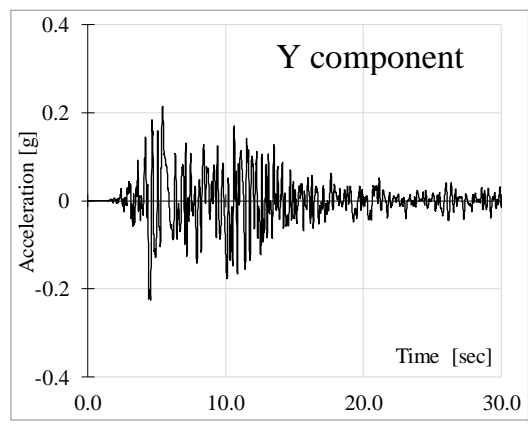

(b)

Figure 7: Earthquake signals applied along the longitudinal (a) and transversal (b) directions of the arch.

The study shows damage tending to be uniform along each bed joint, with damage being of a smaller magnitude along the head joints. Generally, up to the point of collapse, the behaviour under earthquake acceleration can be observed to be similar to that of cyclic loading, with the $3^{\text {rd }}$ hinge tending to form at a similar load and displacement as that experimentally. As the fourth hinge begins to form, and collapse begins, the base shear varies sharply and at times is observed to be larger than at the formation of the hinges. This is in part due to the collapsing vault imparting large forces on its supports as the mechanism was formed. The main results of the analyses are summarised in Table 4. Comparing the results from the two simulations EQ1.0 and EQ1.0x, it can be seen that there is minimal difference in the load capacities obtained, with the vault accelerated in both directions (EQ1.0) actually reaching a slightly higher load at collapse of $4.32 \mathrm{kN}$ compared with $4.23 \mathrm{kN}$ for EQ1.0x. This demonstrates that the acceleration in the y-direction does not contribute significantly to the collapse load in $\mathrm{x}$ or to the failure mechanism observed. As discussed above, past the formation of 4 hinges, the rotation of blocks due to the y acceleration becomes noticeable. This indicates testing in only one directing and using a strip model in the previous section is justified for this type of barrel vault. The load at the formation of 4 hinges tended to be slightly higher than that obtained experimentally, which could be related to the dynamic effects of base acceleration. 


\begin{tabular}{llccccc}
\hline Parameter & & EQ0.5 & EQ1.0 & EQ1.5 & EQ1.0x & Experiments \\
\hline PGA x direction & {$[\mathrm{g}]$} & 0.16 & 0.32 & 0.48 & 0.32 & - \\
PGA y direction & {$[\mathrm{g}]$} & 0.11 & 0.22 & 0.33 & 0.00 & - \\
Peak base shear x & {$[\mathrm{kN}]$} & 1.78 & 4.32 & $4.78(3.89)$ & 4.23 & 3.76 \\
Peak base shear y & {$[\mathrm{kN}]$} & 1.15 & 2.67 & 4.29 & 0.00 & - \\
Max displacement x & {$[\mathrm{mm}]$} & 0.28 & 1.96 & $7.29(2.31)$ & 3.57 & 0.84 \\
Max displacement y & {$[\mathrm{mm}]$} & 0.10 & 0.43 & $1.26(0.73)$ & 0.00 & - \\
\hline
\end{tabular}

Table 4: Maximum peak ground accelerations leading to the formation of a four-hinge mechanism in the vault.

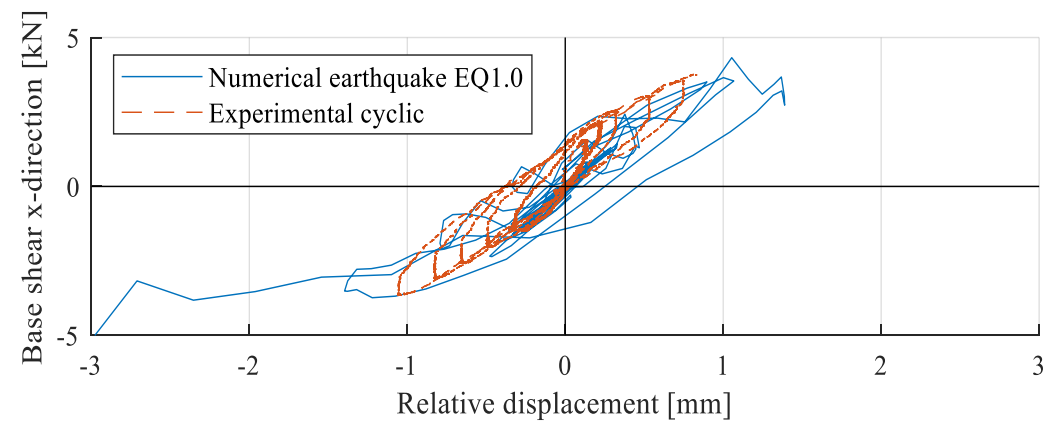

(a)

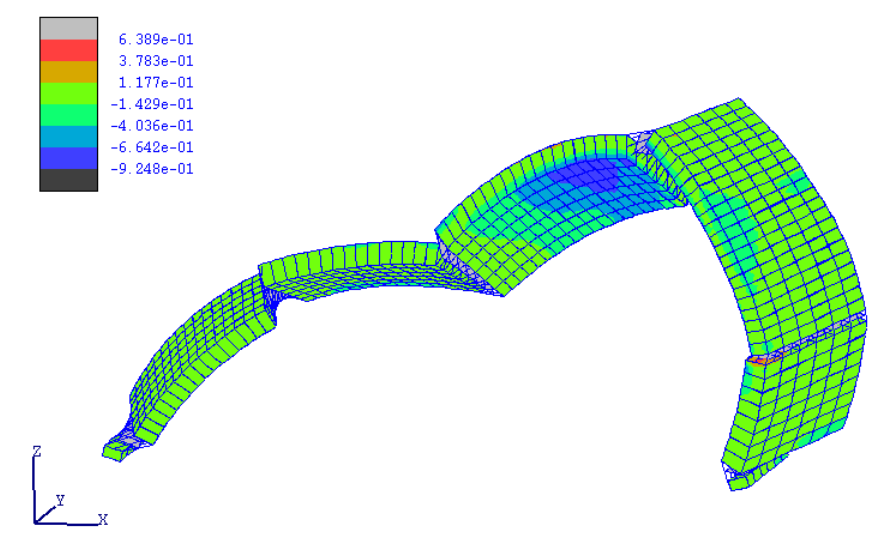

(b)

Figure 8: (a) Total shear-crown horizontal displacement under base acceleration EQ1.0; (b) Failure mechanism under base acceleration EQ1.5 (displacements scaled by 100).

\subsection{The shear stiffness of barrel vaults}

Masonry barrel vaults represent the floor diaphragms of numerous historical buildings. Their shear behaviour influences the local and global response of the structure and its seismic performance. In this section, the performance of a barrel vault specimen under shear loading is numerically investigated considering the effects of accumulated damage caused by earthquake motions.

The same geometrical layout of the barrel vault investigated in Section 5 but with a width equal to the arch span $(3980 \mathrm{~mm})$ is considered. The nonlinear model is first subjected to the $X$ and $\mathrm{Z}$ component of the Irpinia earthquake. At the end the motion, a quasi-static shear drift is applied at the base of the two skewbacks. Four amplification factors, 50\% and 75\%, $85 \%$ and $100 \%$ are chosen to scale the original signal in order to cause plastic damage but no structural collapse. 
In Figure 9, the relative displacement between the two skewbacks is plotted for each model versus the external shear load. In the graph, the curve of the undamaged vault is also plotted for the comparison. The damaged models show a brittle behaviour with a lower displacement capacity when compared to the undamaged vault. The ultimate shear displacement of the vault decreases as the PGA of the seismic input increases.

The failure mechanisms of the undamaged vault and the damaged vault (75\% of signal) are reported in Figure 10a and Figure 10b, respectively. The undamaged model shows a failure mechanism characterised by the formation of 4 significant cracks along the mortar joints developing from the lateral faces of vaults. The cracks propagate towards the middle of the vault following a diagonal path (Figure 10a). The damaged vaults show a different failure mechanism, characterised by the sliding at the skewbacks leading to a rigid rotation of the vault (Figure 10b).

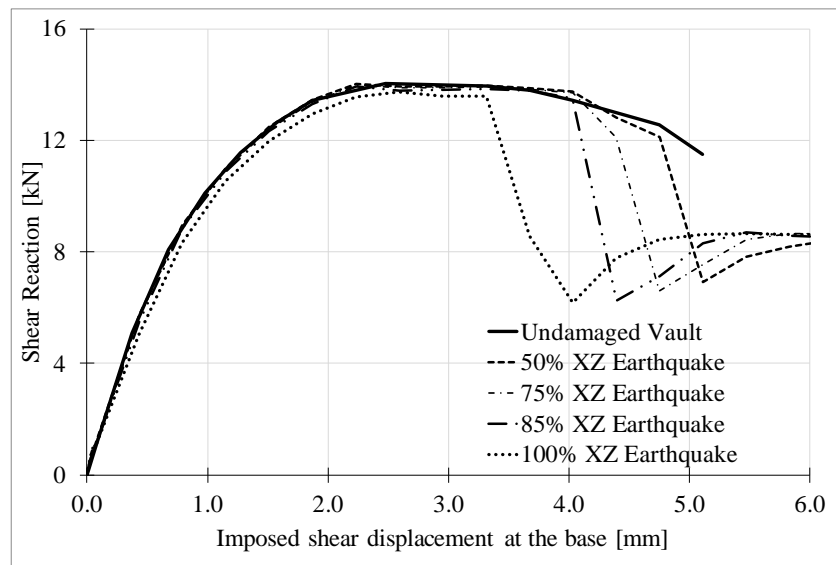

Figure 9: Shear reaction - deformation curves for different earthquake intensities.
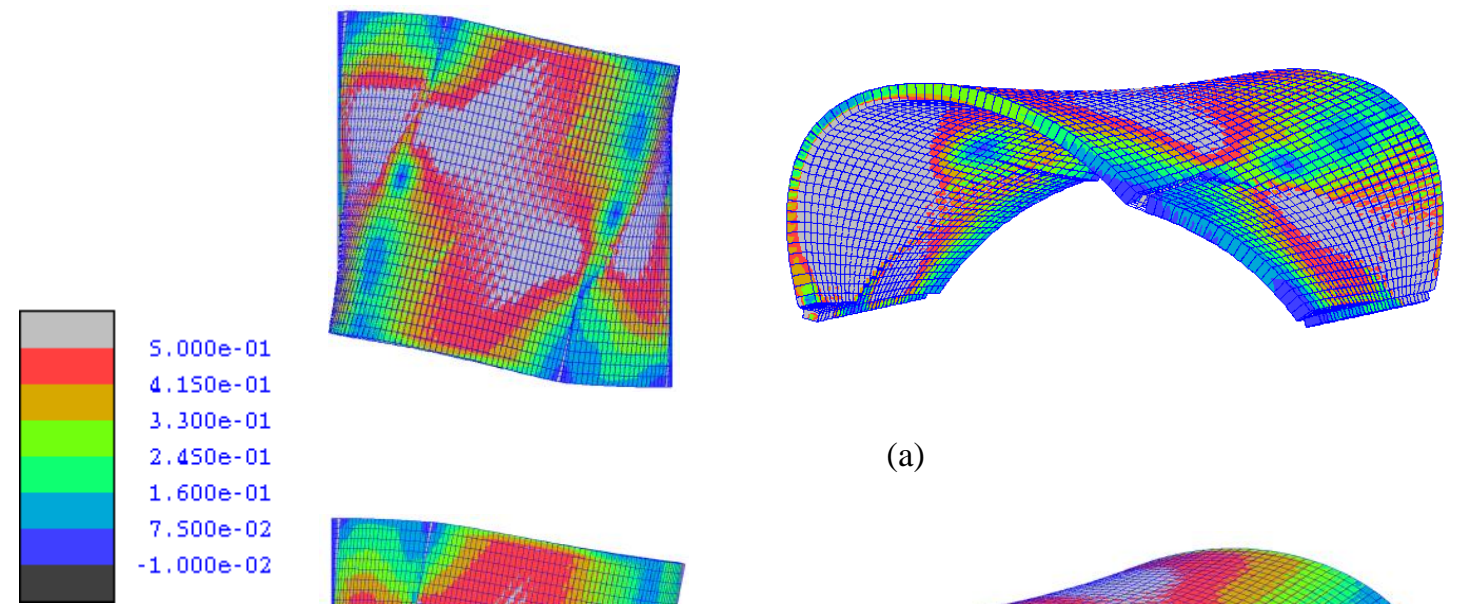

(a)
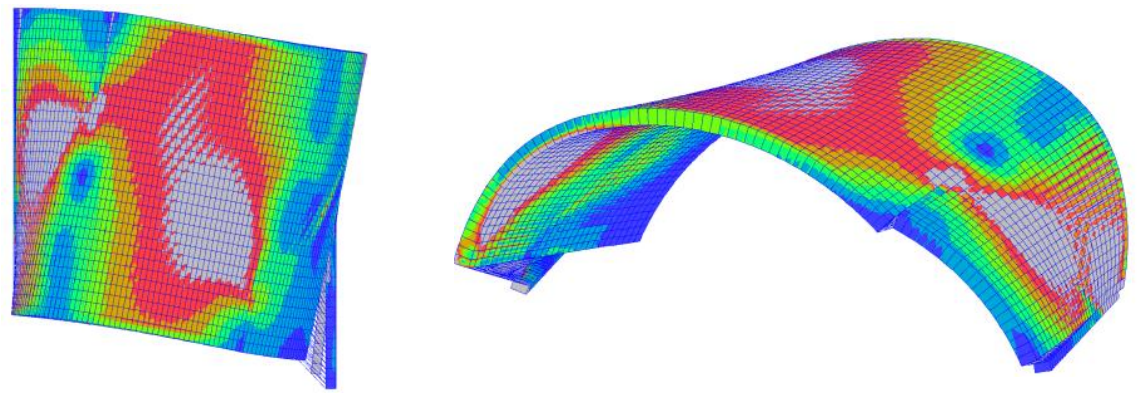

(b)

Figure 10: Shear failure and Von Mises stress (in MPa): (a) undamaged vault, (b) damaged vault. 


\section{CONCLUSIONS}

This study applies a detailed meso-scale model to simulate unreinforced masonry vaults subjected to earthquake loading. Both quasi-static cyclic loads and base accelerations are considered. The model simulates each brick by means of 20-noded elastic solid brick elements interacting by means of 16-noded interface elements. The effective mortar bond is modelled using two different types of interfaces to represent either the mortar bed joints or to simulate the cracks passing the bricks. The numerical results are compared to experimental findings obtained by means of a novel test setup to apply cyclic horizontal forces proportional to the mass of the vault. The meso-scale model is found to be effective in capturing the complex failure modes and predicting crack locations in unreinforced vaults. In the last part of the paper, the influence of different magnitudes of earthquake, including the resulting damage, on the shear deformability and shear strength of the investigated vault specimen is evaluated. The results show that previous damage can reduce significantly the shear displacement capacity of the vault potentially hindering its ability to act as an effective floor/roof diaphragm.

\section{REFERENCES}

[1] Parisi, F. and Augenti, N. Earthquake damages to cultural heritage constructions and simplified assessment of artworks. Engineering Failure Analysis (2013) 34:735-760.

[2] Milani, E., Milani, G., and Tralli, A. Limit analysis of masonry vaults by means of curved shell finite elements and homogenization. International Journal of Solids and Structures (2008) 45(20): 5258-5288.

[3] Casapulla, C., and D'Ayala, D. Lower bound approach to the limit analysis of 3D vaulted block masonry structures. Computer Methods in Structural Masonry (2001) 5: 177-183.

[4] Heyman, J. The Stone Skeleton: Structural Engineering of Masonry Architecture. Cambridge, Cambridge University Press (1995).

[5] Ramaglia, G., Lignola, G. P. and Prota, A. Collapse analysis of slender masonry barrel vaults. Engineering Structures (2016) 117:86-100.

[6] Macorini, L. and Izzuddin, B.A. A non-linear interface element for 3D mesoscale analysis of brick-masonry structures. International Journal for numerical methods in Engineering (2011) 85(12):1584-1608.

[7] Minga, E., Macorini, L. and Izzuddin, B. A. A 3D mesoscale damage-plasticity approach for masonry structures under cyclic loading. Meccanica (2018) 53(7): 1591-611.

[8] Zhang, Y., Macorini, L. and Izzuddin, B. A. Mesoscale partitioned analysis of brickmasonry arches. Engineering Structures (2016) 124: 142-166.

[9] Tubaldi, E., Macorini, L. and Izzuddin B. A. Three-dimensional mesoscale modelling of multi-span masonry arch bridges subjected to scour. Engineering Structures (2018) 165: 486-500.

[10] Minga, E., Macorini, L., Izzuddin, B.A. and Calio', I. Macromodeling, In: B. Ghiassi and G. Milani (Eds.): Numerical Modeling of Masonry and Historical Structures, from Theory to Application, Woodhead Publishing Series in Civil and Structural Engineering (2019) pp. 263-294.

[11] Chisari, C., Macorini, L. and Izzuddin, B.A. Multiscale model calibration by inverse analysis for nonlinear simulation of masonry structures under earthquake loading. International Journal for Multiscale Computational Engineering (2020) 18(2).

[12] Stablon, T., Sellier, A., Domede, N., Plu, B. and Dieleman, L. Influence of building process on stiffness: numerical analysis of a masonry vault including mortar joint shrinkage 
and crack re-closure effect. Materials and Structures (2012) 45(6): 881-898.

[13] Gattesco, N., Amadio, C. and Bedon, C. Experimental and numerical study on the shear behavior of stone masonry walls strengthened with GFRP reinforced mortar coating and steel-cord reinforced repointing. Engineering Structures (2015) 90: 143-157.

[14] Gattesco, N., Boem, I. Review of experimental tests and numerical study on masonry vaults reinforced through fiber-reinforced mortar coating. Bulletin of Earthquake Engineering (2019) 17(7): 4027-4048

[15] Cannizzaro, F., Pantò, B., Caddemi, S., and Caliò, I. A Discrete Macro-Element Method (DMEM) for the nonlinear structural assessment of masonry arches. Engineering Structures (2018) 168: 243-256.

[16] Pantò, B., Cannizzaro, F., Caddemi, S., Caliò, I., Chácara, C., and Lourenço, P. B. Nonlinear modelling of curved masonry structures after seismic retrofit through FRP reinforcing. Buildings (2017) 7(3): 79.

[17] Gattesco, N., Boem, I. and Andretta, V. Experimental behaviour of non-structural masonry vaults reinforced through fibre-reinforced mortar coating and subjected to cyclic horizontal loads. Engineering Structures (2018) 172: 419-431.

[18] Jokhio, G.A. and Izzuddin, B.A. A dual super-element domain decomposition approach for parallel nonlinear finite element analysis. International Journal for Computational Methods in Engineering Science and Mechanics 2015 16(3): 188-212.

[19] Izzuddin, B.A. Nonlinear dynamic analysis of framed structures, Imperial College London (University of London) (1991).

[20] Milani, G. 3D upper bound limit analysis of multi-leaf masonry walls. International Journal of Mechanical Sciences (2008) 50(4): 817-36.

[21] Chisari, C., Macorini, L., Amadio, C. ans Izzuddin, B. A. Identification of mesoscale model parameters for brick-masonry. International Journal of Solids and Structures (2018) 146: 224-240.

[22] Chisari, C., Macorini, L., Izzuddin, B. A. and Amadio, C. Experimental-numerical strategies for the calibration of detailed masonry models. 10th International Masonry Conference, IMC (2018) July 9, 2018 - July 11. 2018, Milan, Italy, International Masonry Society. pp.1732-1745.

[23] Ambraseys, N., Smit P., Sigbjörnsson R., Suhadolc P., and Margaris. B. Internet-Site for European Strong-Motion Data (2001), http://www.isesd.cv.ic.ac.uk. 